\title{
Population prevalence, incidence, and predictors of atrial fibrillation in the Renfrew/Paisley study
}

\author{
S Stewart, C L Hart, D J Hole, J J V McMurray
}

\begin{abstract}
Objectives-Though atrial fibrillation (AF) is an important cause of cardiovascular morbidity, there are few large epidemiological studies of its prevalence, incidence, and risk factors. The epidemiological features of $\mathrm{AF}$ are described in one of the largest population cohorts ever studied. Methods-The prevalence and incidence of AF were studied in the Renfrew/Paisley population cohort of 15406 men and women aged 45-64 years living in the west of Scotland. This cohort was initially screened between 1972 and 1976 and again between 1977 and 1979. Incident hospitalisations with $\mathrm{AF}$ in the 20 year period following initial screening were also studied.

Results-The population prevalence of AF in this cohort was 6.5 cases/1000 examinations. Prevalence was higher in men and older subjects. In those who were rescreened, the four year incidence of $\mathrm{AF}$ was 0.54 cases/1000 person years. Radiological cardiomegaly was the most powerful predictor of new AF (adjusted odds ratio 14.0). During 20 year follow up, 3.5\% of this cohort was discharged from hospital with a diagnosis of AF; the rate of incident hospitalisation for AF was 1.9 cases/1000 person years. Radiological cardiomegaly (adjusted odds ratio 1.46) and systolic blood pressure (adjusted odds ratio 2.1 for $\geqslant 169 \mathrm{~mm} \mathrm{Hg}$ ) were independent predictors of this outcome.

Conclusions-Data from one of the largest epidemiological studies ever undertaken confirm that $\mathrm{AF}$ has a large population prevalence and incidence, even in middle aged people. More important, it was shown that the long term incidence of hospitalisation related to AF is high and that two simple clinical measurements are highly predictive of incident $\mathrm{AF}$. These findings have important implications for the prevention of AF.
\end{abstract}

(Heart 2001;86:516-521)

Keywords: atrial fibrillation; epidemiology; systolic blood pressure; cardiac volume

Though atrial fibrillation (AF) is an important cause of stroke, heart failure, and death, few large population based epidemiological studies have reported its prevalence and, particularly, incidence. The two largest studies have been carried out in the USA. The Framingham heart study started biennial examination of 5070 men and women aged 28-62 years and free of cardiovascular disease in $1948 .^{1}$ The cardiovascular health study examined 5201 adults aged 65 years or older annually, on four occasions, between 1989 and 1993. ${ }^{23}$

The Renfrew/Paisley study is one of the largest epidemiological studies ever undertaken. Its population cohort of 15406 middle aged men and women residing in the west of Scotland were initially examined between 1972 and 1976 and then re-examined between 1977 and 1979. ${ }^{4}$ Using the unique and accurate Scottish record linkage system, we have been able to identify all hospitalisations and deaths occurring within this large cohort over the 20 years after their initial examination. ${ }^{6}$

Using these data, we report the population prevalence and incidence of $\mathrm{AF}$ in this (initially) middle aged cohort. We also report the rate of incident hospitalisations associated with a diagnosis of AF during 20 years of follow up. In addition, we describe the characteristics of subjects with and without baseline $\mathrm{AF}$ and the predictors of the subsequent development of $\mathrm{AF}$ in those in sinus rhythm at their initial examination. These data are important in providing a more contemporary and comprehensive European perspective on this important problem, especially as the epidemiology of cardiovascular disease can vary geographically and over time. This information is also important in understanding how $\mathrm{AF}$ and its associated morbidity might be prevented.

\section{Methods}

STUDY POPULATION

All data concerning the epidemiological features of AF were obtained from the Renfrew/ Paisley study; the purpose, design, and methods of which have been published previously. ${ }^{4}$

This study examined middle aged men $(\mathrm{n}=7052)$ and women $(\mathrm{n}=8354)$ residing in a compact urban area comprising the two towns of Renfrew and Paisley in the west of Scotland. During $1972-6,80 \%$ of the target population aged 45-64 years was screened. During 1977-9, a mean (SD) of 4.1 (.75) years following initial screening, about $60 \%$ of survivors (8532 subjects) were rescreened.

\section{BASELINE DATA}

During baseline screening, subjects completed a battery of health questionnaires and diagnostics tests examining their health status and subsequent risk of developing cardiorespiratory disease. In addition to basic demographic data, each subject's social class was determined by their current occupation using the Registrar General's classification (manual social class was defined as social classes IIIM to V). ${ }^{7}$ The extent of deprivation was determined by the Carstairs deprivation index. ${ }^{8}$ The Rose angina 
questionnaire was used to determine the presence of angina pectoris (classified as none, possible or definite). ${ }^{9}$ Evidence of chronic bronchitis was assessed using the Medical Research Council's bronchitis questionnaire. ${ }^{10}$ Subjects were also asked about their medical history and current status. This included questions about the presence of or previous treatment for cardiorespiratory disease states such as hypertension, asthma, diabetes, and stroke in addition to known risk factors for the development of cardiorespiratory disease (for example, a detailed smoking history was obtained). Subjects were also asked whether they had symptoms indicative of transient cerebral ischaemia (sudden but transient loss of power to limbs or dysphasia). A physical examination with measurement of blood pressure and height and weight (to enable calculation of body mass index in $\mathrm{kg} / \mathrm{m}^{2}$ ) was undertaken. Chest radiography and vitalography were also performed to calculate cardiothoracic ratio and forced expiratory volume in one second $\left(\mathrm{FEV}_{1}\right)$. Cardiomegaly was defined as a cardiothoracic ratio of $\geqslant 0.55$. An adjusted $\mathrm{FEV}_{1}$ score was calculated as a percentage of the "expected" $\mathrm{FEV}_{1}$ score (derived from a linear regression equation of age and height for men and women separately from a healthy subset of the population who were non-smokers and had no respiratory symptoms) and the actual $\mathrm{FEV}_{1}$ score. ${ }^{11}$ A non-fasting venous blood sample was also obtained for the measurement of plasma cholesterol ( $\mathrm{mmol} / \mathrm{l})$ and glucose concentration ( $\mathrm{mmol} / \mathrm{l})$. It should be noted, however, that not all participants were subject to every diagnostic test.

ATRIAL FIBRILLATION DETECTED AT SCREENING During screening, a baseline six lead ECG was recorded. ECGs were subsequently classified by a cardiologist according to the Minnesota coding system. ${ }^{12}$ All cases of AF (Minnesota code 8.3) and ECG abnormalities indicative of past myocardial infarction (MI), active myocardial ischaemia, and left ventricular hypertrophy were also identified.

\section{INCIDENT HOSPITALISATION DURING 20 YEAR} FOLLOW UP

All subjects within the Renfrew/Paisley cohort who were discharged from hospital within 20

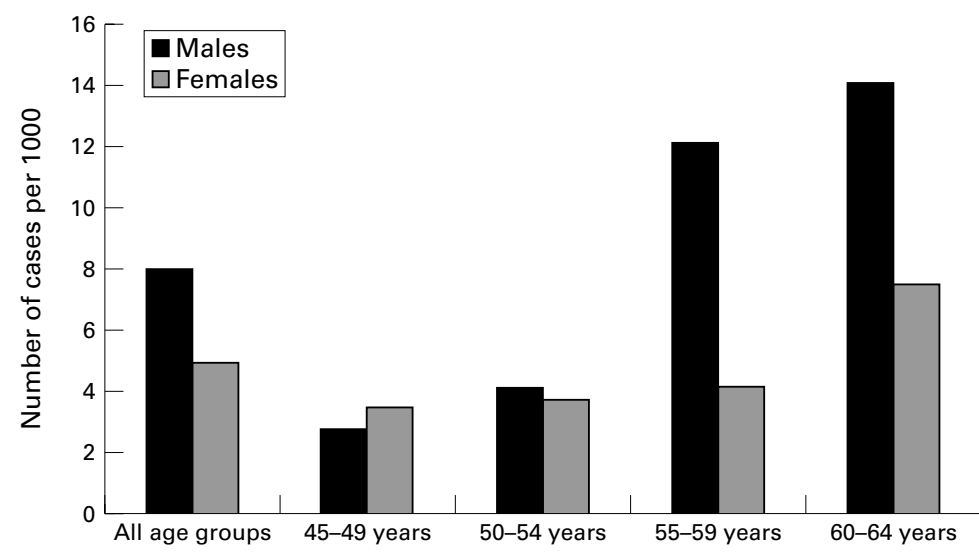

Figure 1 Age and sex specific prevalence of atrial fibrillation $(A F)$ in a population cohort from the west of Scotland. years of their original screening date with a diagnostic coding of AF (International classification of diseases, ninth revision (ICD-9) 427.3 or the equivalent ICD-8 coding for AF before 1978 , in any one of six coding positions) were identified. ${ }^{13}$ These data obtained were directly from the Information and Statistics Division of the National Health Service in Scotland, which collects and collates data on all hospital discharges, on an individual basis, through the Scottish Morbidity Record Scheme. ${ }^{6}$ Regular auditing of these data suggests that coding data are $90 \%$ accurate overall. ${ }^{14}$

\section{STATISTICAL ANALYSIS}

The population prevalence of AF was calculated as the number of detected cases per 1000 examinations. The population incidence of $\mathrm{AF}$ was calculated as the number of new cases per 1000 person years of follow up in those in sinus rhythm at initial screening and who were subject to a re-examination. The rate of incident hospitalisation for $\mathrm{AF}$ was calculated as the number of new cases per 1000 person years during 20 years' follow up of the entire cohort.

Baseline characteristics of subjects with and without $\mathrm{AF}$ at baseline were compared on an age adjusted basis. Categorical variables were age standardised by the direct method using the male and female study populations as the standards, and age adjusted means for continuous variables were calculated using PROC GLM of the SAS system (SAS Institute Inc, Cary, North Carolina, USA).

Multiple logistic regression models were constructed using the initial entry of all variables and stepwise rejection of variables using a significance threshold level of $\mathrm{p}<0.05$. For each categorical variable in the model, the lowest class was set at unity and all adjusted odds ratios (OR) and 95\% confidence intervals (CI) are relative to this class. To evaluate the influence of a large number of missing data for cardiothoracic ratio and blood glucose concentration ( $\mathrm{n}=675$ and 4703, respectively) separate models were constructed in their presence and absence. Except for that mentioned above, all analyses were performed using SPSS for Windows (version 9.0) (SPSS Inc, Chicago, Illinois, USA).

\section{Results}

PREVALENCE OF ATRIAL FIBRILLATION

Analysis of ECG data for the original cohort of men and women aged 45-64 years ( $\mathrm{n}=15406)$ found $100(0.65 \%$; 95\% CI 0.53 to $0.79 \%$ ) documented cases of AF.

Prevalence of $\mathrm{AF}$ increased with age and there were more cases detected in men (53 of $7052)$ than women (47 of 8354). In the subset of subjects who participated in the second survey of this cohort $(n=8532)$ there were 46 $(0.54 \%, 95 \%$ CI 0.40 to $0.72 \%)$ documented cases of AF. Figure 1 summarises the overall prevalence of $\mathrm{AF}$ according to age and sex using the combined data from the two screening periods. 
Table 1 Age adjusted characteristics of the cohort according to the presence or absence of atrial fibrillation $(A F)$ at baseline

\begin{tabular}{|c|c|c|c|c|}
\hline & \multicolumn{2}{|c|}{$\operatorname{Men}(n=7052)$} & \multicolumn{2}{|c|}{ Women $(n=8354)$} \\
\hline & $A F(n=53)$ & Rest $(n=6999)$ & $A F(n=47)$ & Rest $(n=8307)$ \\
\hline \multicolumn{5}{|l|}{ Demographic profile } \\
\hline Mean age (years) & 57.0 & $54.1^{\star \star \star}$ & 56.1 & $54.4^{\star}$ \\
\hline Manual social class (\%) & 74.9 & $68.9^{\star}$ & 56.6 & 57.1 \\
\hline Deprivation category 5-7 (lowest) (\%) & 45.5 & 58.1 & 66.5 & 58.5 \\
\hline \multicolumn{5}{|l|}{ Cardiovascular risk factors } \\
\hline History of stroke (\%) & 7.6 & $1.3^{\star}$ & 7.1 & $1.2^{\star \star \star}$ \\
\hline Possible or definite angina (\%) & 28.4 & 31.6 & 48.7 & $24.5^{\star \star \star}$ \\
\hline Possible transient cerebral ischaemia (\%) & 27.9 & $9.8^{\star \star \star}$ & 19.8 & $9.7^{\star \star}$ \\
\hline Current or former smoker (\%) & 79.0 & 81.2 & 65.8 & 54.1 \\
\hline Mean cholesterol $(\mathrm{mmol} / \mathrm{l})$ & 5.83 & 5.86 & 5.82 & $6.43^{\star \star}$ \\
\hline History of diabetes $(\%)$ & 0 & 1.3 & 3.1 & 1.2 \\
\hline \multicolumn{5}{|l|}{ Clinical profile } \\
\hline Mean body mass index $\left(\mathrm{kg} / \mathrm{m}^{2}\right)$ & 26.5 & 25.9 & 24.4 & 25.8 \\
\hline Mean systolic blood pressure $(\mathrm{mm} \mathrm{Hg})$ & 143.1 & 148.5 & 151.6 & 150.2 \\
\hline Mean diastolic blood pressure ( $\mathrm{mm} \mathrm{Hg}$ ) & 84.1 & 86.0 & 89.1 & $85.1^{\star}$ \\
\hline Mean cardiothoracic ratio & 0.53 & $0.47^{\star \star \star}$ & 0.58 & $0.48^{\star \star \star}$ \\
\hline Mean blood sugar $(\mathrm{mmol} / \mathrm{l})$ & 5.25 & 5.15 & 6.46 & $5.07^{\star}$ \\
\hline Mean adjusted $\mathrm{FEV}_{1}$ (\% predicted) & 79.0 & $88.7^{\star \star \star}$ & 71.2 & $92.5^{\star \star \star}$ \\
\hline Chronic bronchitis (\%) & 16.8 & $5.7^{\star \star}$ & 7.7 & 4.1 \\
\hline Pathological Q waves on ECG (\%) & 5.3 & $3.4^{\star}$ & 0 & 2.0 \\
\hline Myocardial ischaemia on ECG (\%) & 10.1 & $5.0^{\star \star \star}$ & 43.2 & $6.0^{\star \star \star}$ \\
\hline Left ventricular hypertrophy on ECG (\%) & 5.3 & 5.6 & 21.3 & $7.0^{\star \star \star}$ \\
\hline LBBB on ECG $(\%)$ & 11.5 & $7.7^{\star \star}$ & 44.4 & $6.8^{\star \star \star}$ \\
\hline
\end{tabular}

For comparison between groups: $t$ test for continuous variables and $\chi^{2}$ test for discrete variables. Difference between groups: ${ }^{\star} \mathrm{p}<0.05 ;{ }^{\star \star} \mathrm{p}<0.01{ }^{\star \star \star} \mathrm{p}<0.001$.

$\mathrm{FEV}_{1}$, forced expiratory volume in one second; LBBB, left bundle branch block.

DEMOGRAPHIC AND CLINICAL ASSOCIATES OF ATRIAL FIBRILLATION

Table 1 shows the characteristics of this population cohort at baseline according to the presence or absence of $\mathrm{AF}$ on an age adjusted basis. Both men and women in AF were older and more likely to have a history of stroke, symptoms indicative of possible transient cerebral ischaemia, ECG evidence of myocardial ischaemia, and left bundle branch block and cardiomegaly as determined by chest radiography. They were also more likely to have a lower adjusted $\mathrm{FEV}_{1}$. Women but not men in $\mathrm{AF}$ were found to have higher diastolic blood pressure and blood sugar concentrations, lower total cholesterol concentrations, and a history of angina, and were more likely to have ECG evidence of left ventricular hypertrophy. Men but not women in AF were more likely to have symptoms indicative of chronic bronchitis and ECG evidence of past MI (pathological Q waves) and to come from a manual social class. Of the 100 subjects with AF, 13 reported exertional dyspnoea with all 13 fulfilling the Medical Research Council criteria for chronic bronchitis. ${ }^{11}$

Table 2 summarises the independent correlates of $\mathrm{AF}$ according to baseline screening data. Male sex, a history of stroke, and ECG evidence of myocardial ischaemia were independently associated with AF. Overall, however, cardiomegaly was the strongest correlate of AF. When this variable was excluded from the model, older age also appeared to be independently associated with AF (OR 2.1, 95\% CI 1.1 to 10.2 per decade, $\mathrm{p}<0.05)$.

INCIDENCE OF ATRIAL FIBRILLATION DETECTED AT FOLLOW UP SCREENING

Of the 8532 subjects who participated in the follow up screening of the Renfrew/Paisley cohort, 14 men and five women had newly documented AF. Figure 2 shows the age (based on age at first screening) and sex specific rate of incident cases of AF per 1000 person years of follow up. The rate of incident cases increased notably with age and was greater in men than in women. Paired analysis of data collected during the first and follow up examinations found no significant changes in systolic and diastolic blood pressure, cardiothoracic ratio, blood sugar concentration, plasma cholesterol concentration, and adjusted $\mathrm{FEV}_{1}$ for those who developed new AF. For example, of the 19 subjects with new AF, eight had radiographic cardiomegaly detected on both occasions. However, four subjects reported new angina pectoris. Thus, 12 of 19 subjects with new AF

Table 2 Independent correlates of $A F$ at baseline

\begin{tabular}{|c|c|c|c|c|c|c|}
\hline \multirow[b]{2}{*}{ Correlates } & \multicolumn{2}{|l|}{ Men } & \multicolumn{2}{|c|}{ Women } & \multicolumn{2}{|c|}{ Total cohort } \\
\hline & $O R$ & $95 \% C I$ & $O R$ & $95 \% C I$ & $O R$ & $95 \% C I$ \\
\hline Male sex & _- & _- & _- & - & 1.8 & $(1.2 \text { to } 2.8)^{\star \star}$ \\
\hline Cardiomegaly & 7.3 & (3.9 to 13.4 ) & 17.4 & (8.7 to 34.8$)$ & 13.0 & $(8.3 \text { to } 20.2)^{\star \star \star}$ \\
\hline Chronic bronchitis & 2.5 & (1.2 to 5.4$)$ & - & - & 2.2 & $(1.1 \text { to } 4.2)^{\star}$ \\
\hline Left ventricular hypertrophy & - & - & - & - & 4.2 & $(1.5 \text { to } 12.3)^{\star \star \star}$ \\
\hline Myocardial ischaemia & 2.2 & (1.1 to 4.7$)$ & 5.6 & (2.9 to 10.8$)$ & 4.5 & $(2.7 \text { to } 7.4)^{\star \star \star \star}$ \\
\hline History of stroke & - & - & 5.2 & (1.8 to 15.1$)$ & 3.9 & $(1.7 \text { to } 8.7)^{\star \star \star}$ \\
\hline Blood sugar $\geqslant 7.0 \mathrm{mmol} / 1$ & - & - & 5.4 & (2.2 to 13.3$)$ & 3.1 & $(1.6 \text { to } 6.0)^{\star \star \star}$ \\
\hline Possible transient cerebral ischaemia & 2.4 & $(1.2$ to 4.5$)$ & - & - & - & - \\
\hline
\end{tabular}

Significance based on multivariate analysis: ${ }^{\star} \mathrm{p}<0.05 ;{ }^{\star \star} \mathrm{p}<0.01 ;{ }^{\star \star \star} \mathrm{p}<0.001$

$\mathrm{OR}$, odds ratio; CI, confidence interval. 


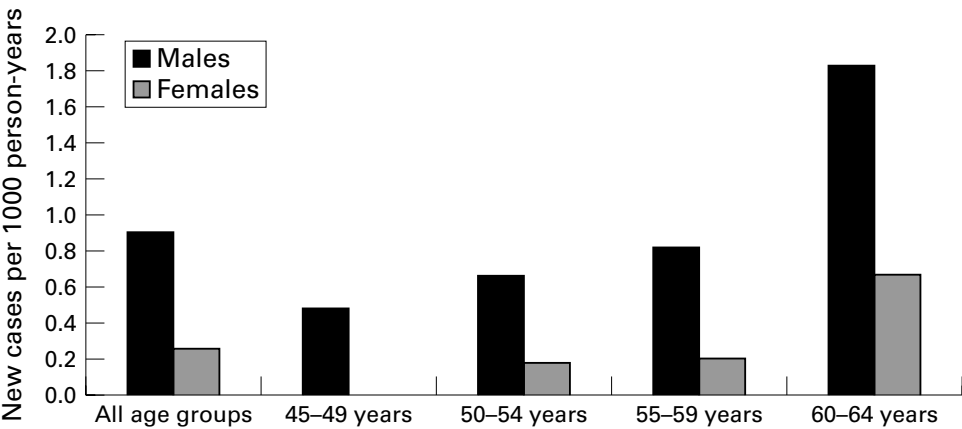

Figure 2 Rate of new incident cases of $A F$ detected during rescreening of 8532 men and women (34 891 person years of follow up). (Age groups are based on age at baseline.)

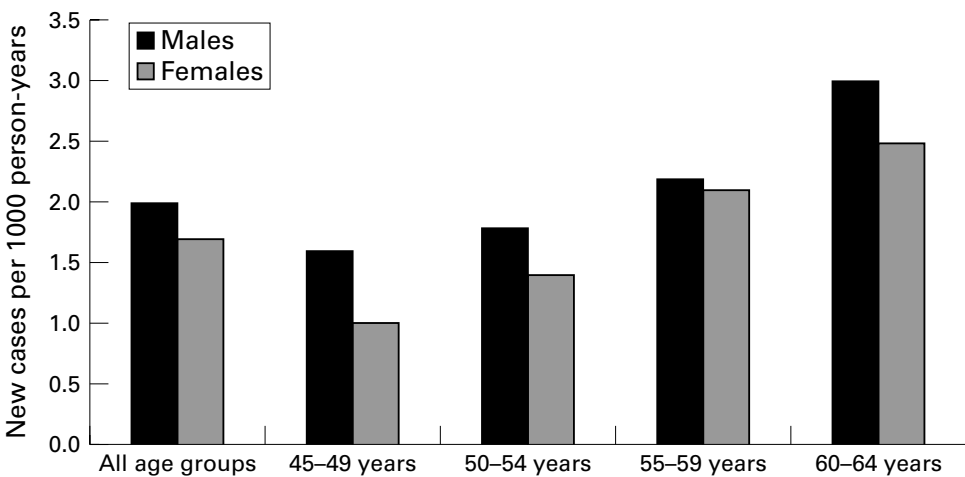

Figure 3 Rate of incident AF hospitalisation in 15306 men and women during 20 year follow up. (Age groups are based on age at baseline.)

had a history of angina. Five (including the four with new onset angina) subjects had newly documented myocardial ischaemia on their repeat ECG. Although two subjects no longer had ECG changes indicative of myocardial ischaemia during the second survey, 13 of the 19 subjects with newly documented AF had some manifestation of myocardial ischaemia (angina or ECG changes) during the second examination. Moreover, five subjects reported new symptoms indicative of transient cerebral ischaemia (making a total of six subjects with this problem), though there were no new cases of stroke.

INDEPENDENT PREDICTORS OF INCIDENT ATRIAL FIBRILLATION

According to the multivariate analysis, male sex (OR 3.4, 95\% CI 1.1 to 10.2), greater age (OR $1.29,95 \%$ CI 1.2 to 1.4 /decade), and cardiomegaly (OR $14.0,95 \%$ CI 5.1 to 10.2 ) were the only independent predictors $(\mathrm{p}<0.05)$ of new AF. In the absence of cardiomegaly, all of the above variables were retained in the logistic regression model, with the addition of ECG evidence of myocardial ischaemia (OR 4.1, 95\% CI 1.2 to 14.2 ) detected at baseline.

INCIDENT HOSPITALISATIONS ASSOCIATED WITH A DIAGNOSIS OF ATRIAL FIBRILLATION

As the age of the Renfrew/Paisley cohort ranged from 45-64 years at baseline, we were able to document incident hospitalisations for $\mathrm{AF}$ in this cohort up to the age of 84 years. During the first four years of follow up of the original Renfrew/Paisley cohort we found that five of the 19 subjects with new AF were hospitalised. All were coded at discharge with a diagnosis of AF. There were no hospitalisations associated with a diagnosis of $\mathrm{AF}$ in subjects without $\mathrm{AF}$ who had a follow up examination.

During 20 years follow up, 255 of the 6999 men $(3.6 \%, 95 \%$ CI $3.2 \%$ to $4.1 \%)$ and 282 of the 8307 women $(3.4 \%, 95 \%$ CI $3.0 \%$ to $3.8 \%)$ in the Renfrew/Paisley cohort without $\mathrm{AF}$ at baseline were discharged from hospital with a diagnosis of AF. The proportion of men for whom such a hospitalisation was recorded increased from $3.3 \%$ (95\% CI $2.5 \%$ to $3.2 \%$ ) in those initially aged $45-49$ years to $4.2 \%$ (95\% CI $3.3 \%$ to $5.4 \%$ ) in those aged $60-64$ years. The equivalent figures for women were $2.3 \%(95 \%$ CI $1.7 \%$ to $3.0 \%)$ and $4.4 \%(95 \%$ CI $3.5 \%$ to $5.4 \%$ ), respectively. Figure 3 shows the age and sex specific rates of incident hospitalisations with AF per 1000 person years of follow up.

Overall, this cohort recorded 808 hospitalisations where AF was coded in any position during 20 years follow up (38\% of these as the principal diagnosis). The most common concurrent diagnoses (coded in any position at discharge) were heart failure $(38 \%)$, coronary artery disease other than MI (34\%), stroke $(23 \%)$, and MI (14\%). Valvar heart disease was documented in approximately $7 \%$ of cases, while thyroid disease was documented in $<1.5 \%$ of cases.

INDEPENDENT PREDICTORS OF INCIDENT HOSPITALISATION WITH ATRIAL FIBRILLATION Table 3 shows the independent predictors of incident hospitalisation with AF based on original screening data in patients not found to be in $\mathrm{AF}$ at baseline $(\mathrm{n}=15306)$. Once again, age and cardiomegaly were independent predictors for new $\mathrm{AF}$ detected in this manner, although there was little difference between men and women. Other predictors were a history of symptoms indicative of angina and a higher systolic blood pressure recorded at baseline. In the absence of cardiomegaly, a higher body mass

Table 3 Independent predictors of incident AF hospitalisation during 20 year follow up

\begin{tabular}{|c|c|c|c|c|}
\hline \multirow[b]{2}{*}{ Baseline characteristic } & \multicolumn{2}{|c|}{ New AF hospitalisation } & \multicolumn{2}{|c|}{ Multivariate analysis } \\
\hline & Yes $(n=537)$ & No $(n=14869)$ & $p$ Value & OR $(95 \% C I)$ \\
\hline Age (mean (SD) years) ${ }^{\star}$ & $55(6)$ & $54(6)$ & 0.028 & $2.72(1.65$ to 4.49$)$ \\
\hline Possible or definite angina $\nmid$ & $194(36 \%)$ & $4095(28 \%)$ & $<0.001$ & $1.37(1.14$ to 1.67$)$ \\
\hline Cardiomegaly & $68 / 519(13 \%)$ & $1032 / 14212(7 \%)$ & 0.004 & 1.49 (1.14 to 1.98$)$ \\
\hline Systolic BP (mean (SD) $\mathrm{mm} \mathrm{Hg}) \ddagger$ & $155(26)$ & $149(24)$ & $<0.0001$ & $2.06(1.48$ to 2.88$)$ \\
\hline Body mass index (mean (SD) $\mathrm{kg} / \mathrm{m}^{2}$ ) & $26.7(4.5)$ & $25.7(4.6)$ & $<0.009$ & $1.43(1.12$ to 1.79$)$ \\
\hline
\end{tabular}

$\star \mathrm{OR}$ for each additional decade of age; †As determined by Rose angina questionnaire; $¥ \mathrm{OR}$ based on upper quartile of blood pressure (BP) distribution ( $\geqslant 169 \mathrm{mmHg}$ ); $\uparrow \mathrm{OR}$ and significance based on a model without cardiothoracic ratio data and on upper quartile of body mass index distribution $\left(\geqslant 28.1 \mathrm{~kg} / \mathrm{m}^{2}\right)$, otherwise non-significant. 
index was also retained in the final model. Not surprisingly, subjects who were in $\mathrm{AF}$ at baseline were also about three times more likely to be hospitalised with a diagnosis of AF during follow up (15\%; adjusted OR 2.9).

\section{Discussion}

Using data from one of the largest and most contemporary population based epidemiological studies and incorporating a unique system for accurately identifying hospitalisations over a prolonged period, the present study is one of the largest and most comprehensive analyses of the epidemiological features of AF in middle age onwards. In particular, we have been able to identify two simple clinical predictors of future $\mathrm{AF}$, which has implications for prevention of $\mathrm{AF}$ and its associated mortality and for our understanding of the relation between systolic blood pressure and the risk of stroke.

PREVALENCE OF ATRIAL FIBRILLATION:

COMPARISON WITH PREVIOUS STUDIES

Our findings are in keeping with those of the Framingham heart study, which found an initial screening prevalence of 5/1000 in those aged 50-59 years and rising to $18 / 1000$ in those aged $60-69$ years. ${ }^{15-18}$ The prevalence rates in subjects aged 50-59 years in the Renfrew/Paisley cohort were 7.2/1000 in men and 2.9/1000 in women. The male and female rates in those aged 60-69 years were 10.2 and $7.4 / 1000$, respectively, somewhat less than in Framingham. Our findings are also agreement with reports from Denmark, ${ }^{19}$ Iceland, ${ }^{20}$ and the Netherlands ${ }^{21}$ that have described smaller populations.

INCIDENCE OF ATRIAL FIBRILLATION: COMPARISON WITH PREVIOUS STUDIES

Of more interest are our data on the incidence of $\mathrm{AF}$ because of the paucity of data in this regard. The Framingham heart study reported two yearly incidence rates of approximately 1.9 and 0.9/1000 person years in men and women, respectively, aged 50-59 years. ${ }^{15-18}$ Our equivalent rates over four years in those aged 55-64 years were 1.31 and $0.44 / 1000$ person years. Over 38 years of follow up, the Framingham study found an overall incidence of approximately $3 / 1000$ person years in men and $2 / 1000$ person years in women aged $55-64$ years. ${ }^{1}$ We observed a 20 year rate of incident hospitalisation with $\mathrm{AF}$ of 2.1 and $1.7 / 1000$ person years in men and women, respectively, in this age range.

The only other incidence study encompassing subjects in the same age range and with long term follow up is the Manitoba follow up study in Canada, which examined 3983 male aircrew recruits with an average age of 31 years in $1948 .^{22}$ These subjects were followed for 44 years. The incidence rate was $2 / 1000$ patient years overall, being as low as $<0.5 / 1000$ before the age of 50 and rising to $2.3 / 1000$ person years by the age of 60 years.

INCIDENT HOSPITALISATION OVER 20 YEARS

Our rate of incident hospitalisation for all men over 20 years' follow up was 2.0/1000 person years. This almost certainly is an underestimation of its true incidence because we had no means to detect $\mathrm{AF}$ in those who avoided hospitalisation. Consequently, our population incidence over 20 years is likely to have been higher than the hospitalisation rates and, therefore, higher than in either the Framingham. ${ }^{1{ }^{15-18}}$ or Manitoba cohorts. $^{22}$ This is, perhaps, not surprising with regard to the Canadian study, which recruited fit young men, whereas our cohort was unselected and from a population with a high rate of coronary and other cardiovascular disease. ${ }^{4}$ Interestingly, however, it seems that although we found a lower initial prevalence than Framingham, our subjects went on to have a higher long term incidence, again presumably reflecting the impact of other cardiovascular diseases in later years. ${ }^{15-18}$ Indeed, one of the most important findings of our study is the high burden of incident hospitalisation related to $\mathrm{AF}$, with $3 \%$ of men and over $2 \%$ of women aged $45-49$ years at baseline going on to experience such an event in the subsequent two decades of follow up.

CORRELATES OF ATRIAL FIBRILLATION

We were also able to examine the baseline demographic and clinical features of subjects with and without AF and the independent correlates of $\mathrm{AF}$ in this population cohort. As in other studies, we found male sex and existing cardiovascular disease to be independently correlated with AF. We also found chronic lung disease and, in particular, cardiomegaly to be important. We found hyperglycaemia to be a much stronger correlate than in the cardiovascular health study. ${ }^{23}$

PREDICTORS OF NEW ATRIAL FIBRILLATION Of more interest are the predictors of new AF. Here we found age and sex to be important independent predictors, as in other reports. We observed a doubling of risk for each decade of age, in close agreement with the Framingham investigators' findings. ${ }^{1}$ However, we have also been able to show that cardiomegaly, on the chest radiograph, is by far the most powerful predictor in the multivariate analysis, an observation not made previously. In the Framingham study, heart failure and ECG determined left ventricular hypertrophy were the most powerful predictors of incident $\mathrm{AF}$ with a fourto sixfold increase risk due to the former and a three- to fourfold increased risk from the latter. ${ }^{1}$ A later cohort of 1924 subjects aged 50-94 years did undergo echocardiography in the Framingham study, and left atrial size, reduced fractional shortening, and wall thickness were found to increase modestly the risk of developing AF. ${ }^{15-18}$ In contrast, we found that radiological cardiomegaly led to a 14 -fold increase in the likelihood of new AF. These findings support the view that cardiothoracic ratio is a simple and powerful predictor of adverse cardiovascular outcomes. ${ }^{23}$ Therefore, patients with radiological cardiomegaly should, if not already under regular review, be kept under close surveillance from the point of view of their heart rhythm (and, in any case, merit further cardiological investigation). 
Though this population cohort was rescreened only once, after four years, importantly, we have also been able to obtain information on incident hospitalisations with $\mathrm{AF}$ for up to 20 years. Clearly, these data underestimate the true incidence of new $\mathrm{AF}$ in our population, as mentioned earlier. Nevertheless, this manifestation of AF is clearly of interest. Once again, age and cardiomegaly were important predictors, though the latter was much less powerful a predictor for this outcome in the longer term. Of considerable interest was the finding that systolic hypertension was an independent predictor of hospitalisation with $\mathrm{AF}$, approximately doubling the chances of this event. These data are difficult to interpret. Though each hospitalisation had a discharge coding of $\mathrm{AF}$, it was usually a secondary diagnosis. In the approximately 800 such hospitalisations accumulated over 20 years, $\mathrm{AF}$ was the principal diagnosis in $38 \%$ of cases, the most frequent other principal diagnoses being heart failure $(11 \%), \mathrm{MI}(9 \%)$, and stroke $(7 \%)$. The predictive relation we have described may, therefore, merely reflect an indirect association between systolic blood pressure and $\mathrm{AF}$ - for example, the association between systolic blood pressure and MI, and $\mathrm{MI}$ and AF. If, however, there is a direct relation, this may be of considerable importance and raises a number of interesting questions. Can $\mathrm{AF}$ account for some of the relation between systolic blood pressure and stroke or heart failure? This certainly seems to be an area for further investigation.

\section{STUDY LIMITATIONS}

As with any large epidemiological study, there are limitations to our analysis. Baseline information on valvar heart disease and chronic heart failure, both important causes of AF, was not collected. It should be noted, however, that only $13 \%$ of subjects with $\mathrm{AF}$ reported exertional dyspnoea at the time of screening, all of them fulfilling the criteria for chronic bronchitis. Moreover, only three subjects were hospitalised with heart failure within three years of screening and only a small proportion of hospitalisations for $\mathrm{AF}(<5 \%)$ were associated with a concurrent diagnosis of valvar heart disease. In the majority of cases, a single ECG recording was made, meaning that it was not possible to differentiate between paroxysmal and sustained $\mathrm{AF}$, though this limitation is true of other studies also. These data also do not provide information concerning treatment. Lastly, the potential influence of selection bias (in favour of healthier people) as part of the rescreening process is an important caveat when considering incidence data.

\section{CONCLUSIONS}

In summary, the prevalence of AF in Scotland is similar to that in comparable age groups in other countries. The incidence of $\mathrm{AF}$ is also similar, although in the short term (four years) only about a quarter of these cases are associated with a hospital discharge related to $\mathrm{AF}$. In the longer term (20 years) almost $4 \%$ of middle aged men and women will have an incident hospitalisation associated with AF. The most powerful predictor of the future development of this arrhythmia is radiological cardiomegaly, which increases the adjusted risk 14 -fold in the short term and 2.5-fold in the longer term.

Simon Stewart is supported by the National Heart Foundation of Australia. Carole Hart was supported by grants from Chest, Heart, and Stroke Scotland and the Stroke Association.

We gratefully acknowledge the contribution of Pauline Mackinnon, who is responsible for updating and maintaining the Renfrew/Paisley cohort database. Victor M Hawthorne and Charles R Gillis were responsible for the original Renfrew/ Paisley study.

1 Kannel WB, Abbot RD, Savage DD, et al. Epidemiological features of chronic atrial fibrillation: the Framingham study. N Engl F Med 1982;306:1018-24.

2 Furberg CD, Psaty BM, Manolio TA, et al. Prevalence of atrial fibrillation in elderly subjects (the cardiovascular health study). Am $\mathcal{F}$ Cardiol 1994;74:236-41.

3 Psaty BM, Manolio TA, Kuller TM, et al. Incidence of and risk factors for atrial fibrillation in older adults. Circulation 1997;96:2455-61.

4 Hawthorne VM, Watt GC, Hart CL, et al. Cardiorespiratory disease in men and women in urban Scotland: baseline characteristics of the Renfrew/Paisley (Midspan) study population. Scott Med f 1995;40:102-7.

5 Hart CL, Hole DJ, Smith GD. Risk factors and 20-year stroke mortality in men and women in the Renfrew/Paisley study in Scotland. Stroke 1999;30:1999-2007.

6 Kendrick S, Clarke J. The Scottish record linkage system. Health Bull 1993;51:72-9.

7 General Register Office. Classification of occupation 1966. London: HSMO, 1966.

8 Carstairs V, Morris R. Deprivation and health in Scotland. Aberdeen: Aberdeen University Press, 1991.

9 Rose GA. The diagnosis of ischaemic heart pain and intermittent claudication in field surveys. Bull World Health Organ 1962;27:645-58.

10 Medical Research Council. Definition and classification of chronic bronchitis for epidemiological purposes. Lancet 1965;i:775-9.

11 Hole DJ, Watt GC, Davey-Smith G, et al. Impaired lung function and mortality risk in men and women: findings from the Renfrew and Paisley prospective population study. BMJ 1996;313:711-6.

12 Prineas RJ, Crow RS, Blackburn H. The Minnesota code manual of electrocardiographic findings: atandards and procemanual of electrocardiographic findings: atandards and procedures for measu

13 Manual of the international statistical classification of diseases, injuries and causes of death, 9th revision. Geneva: World Health Organization, 1977 .

14 Harley K, Jones C. Quality of Scottish morbidity record (SMR) data. Health Bull 1996;54:410-7.

15 Wolf PA, Abbott RD, Kannel WB. Atrial fibrillation as an independent risk factor for stroke: the Framingham study. Stroke 1991;22:983-98.

16 Benjamin EJ, Levy D, Vaziri SM, et al. Independent risk factors for atrial fibrillation in a population-based cohort. The Framingham heart study. $\mathcal{F A M A} 1994 ; 271: 840-4$.

17 Wolf PA, Benjamin EJ, Belanger AJ, et al. Secular trends in the prevalence of atrial fibrillation: the Framingham study. Am Heart $\mathcal{7} 1996 ; 131: 790-5$.

18 Kannel WB, Wolf PA, Benjamin EJ, et al. Prevalence, incidence, prognosis, and predisposing conditions for atrial fibrillation: population-based estimates. $\mathrm{Am} f \mathrm{C}$ Cardiol 1998;82:2N-9N

19 Boysen G, Nyboe J, Appleyard M, et al. Stroke incidence and risk factors for stroke in Copenhagen, Denmark. Stroke 1988;11:1345-53.

20 Onundarson PT, Thorgeirsson G, Jonmundsson E, et al. Chronic atrial fibrillation: epidemiologic features and 14 year follow-up: a case control study. Eur Heart $f$ 1987;8:521-7.

21 Langenberg M, Hellemons BS, van Ree JW, et al. Atrial fibrillation in elderly patients: prevalence and comorbidity in general practice. BMF 1996;313:1534

22 Krahn AD, Manfreda J, Tate RB, et al. The natural history of atrial fibrillation: incidence, risk factors and prognosis in the Manitoba follow-up study. Am F Med 1995;98:476-84.

23 Sandvik L, Erikssen J, Thaulow E, et al. Heart volume and cardiovascular mortality: a 16 year follow-up study of 1984 healthy middle-aged men. Eur Heart 7 1993;14:592-6.

24 Hemingway H, Shipley M, Christie D, et al. Cardiothoracic ratio and relative heart volume as predictors of coronary heart disease mortality: the Whitehall study 25 year followup. Eur Heart F 1998;19:859-69. 